\title{
A price-responsive dispatching strategy for Vehicle-to-Grid: An economic evaluation applied to the case of Singapore
}

\author{
Dominik Pelzer ${ }^{\mathrm{a}, *, 1}$, David Ciechanowicz ${ }^{\mathrm{a}, 1}$, Heiko Aydt ${ }^{\mathrm{a}}$, Alois Knoll ${ }^{\mathrm{b}}$ \\ a TUM CREATE, 1 CREATE Way, Singapore 138602, Singapore \\ ${ }^{\mathrm{b}}$ Technische Universität München (TUM), Institute for Informatics VI, Robotics and Embedded Systems, Germany
}

\section{H I G H L I G H T S}

- A charging and dispatching strategy for optimizing profits from V2G is presented.

- This optimization strategy builds on temporally resolved electricity market data.

- A case study shows that this method turns a S\$1000 annual loss into a S\$130 profit.

- Sensitivity analyses indicate potential for further increase of profitability.

- Employing this strategy in other countries is assumed to yield much greater profits.

\section{A R T I C L E I N F O}

\section{Article history:}

Received 21 November 2013

Received in revised form

13 January 2014

Accepted 17 January 2014

Available online 25 January 2014

\section{Keywords:}

Vehicle-to-Grid

Electric vehicle

Energy market

Economic viability

Ancillary services

Optimization model

\begin{abstract}
A B S T R A C T
Employing electric vehicles as short-term energy storage could improve power system stability and at the same time create a new income source for vehicle owners. In this paper, the economic viability of this concept referred to as Vehicle-to-Grid is investigated. For this purpose, a price-responsive charging and dispatching strategy built upon temporally resolved electricity market data is presented. This concept allows vehicle owners to maximize returns by restricting market participation to profitable time periods. As a case study, this strategy is then applied using the example of Singapore. It is shown that an annual loss of $S \$ 1000$ resulting from a non-price-responsive strategy as employed in previous works can be turned into a $S \$ 130$ profit by applying the price-responsive approach. In addition to this scenario, realistic mobility patterns which restrict the temporal availability of vehicles are considered. In this case, profits in the range of $S \$ 21-S \$ 121$ are achievable. Returns in this order of magnitude are not expected to make Vehicle-to-Grid a viable business case, sensitivity analyses, however, show that improved technical parameters could increase profitability. It is further assumed that employing the priceresponsive strategy to other national markets may yield significantly greater returns.
\end{abstract}

(c) 2014 Elsevier B.V. All rights reserved.

\section{Introduction}

In a power system, electricity demand and supply are subject to continuous fluctuations which cause deviations from the desired voltage frequency. This requires an instantaneous intervention by the system operator which restores the equilibrium between power demand and supply. Power grid stability is either ensured by power plants which are able to quickly adjust their power output or by storage facilities which serve as buffers for energy excesses or shortages. Most of these solutions, however, are either costly or entail large space, presenting a need for developed concepts that

\footnotetext{
* Corresponding author. Tel.: +65 6601 4015; fax: +65 66940062.

E-mail address: dominik.pelzer@tum-create.edu.sg (D. Pelzer).

1 These authors contributed equally to this work.
}

offer greater economic advantages. This becomes especially vital with growing shares of intermittent renewable energies which will further increase the need for frequency regulation.

As part of a future smart grid, electric vehicles (EV) could play a major role for the fine-tuning of energy demand and supply. On average, a vehicle is parked $23 \mathrm{~h}$ a day [1]. During this time, its battery pack could be employed as a buffer for power excess or shortage by either charging the battery or by feeding electricity back to the grid. This concept termed Vehicle-to-Grid (V2G) was first mentioned in 1997 [2] and has been subject to intensive research in the last two decades. In this context, various theoretical investigations confirmed its effectiveness to improve power grid stability [1,3-7] and several fully functional prototypes where implemented $[5,6,8]$.

For EV owners, V2G could create revenues that would accelerate the amortization of vehicle investment costs. Economic feasibility 
studies have been conducted for different countries which, depending on their assumptions, arrive at different conclusions on the profitability of V2G [1,7-12]. One major drawback of previous analyses is the use of static models that are built on average values of electricity market data [7,9-12]. Electricity prices, however, highly vary during the course of a day, presenting varying scenarios where V2G may yield profits in one time period but result in losses in a different one. These unprofitable periods were incorporated in previous studies which led to an underestimation of achievable profits. The ability to distinguish between profitable and unprofitable time intervals is therefore crucial for maximizing monetary returns. Furthermore, individual travel itineraries impose restrictions on the temporal availability of vehicles. Knowing whether a vehicle will be primarily available during profitable or unprofitable periods is therefore essential to deduce a reliable conclusion on possible profits.

This paper presents a method which builds upon temporarily resolved electricity market data. This allows the emulation of a smart charging/dispatching strategy which aims to maximize V2G profits by avoiding unprofitable time periods. This method furthermore permits investigations on the effects of different realistic mobility patterns which define the times EVs are grid-connected.

As an application of the price-responsive strategy, profits for various scenarios were calculated using the example of Singapore. The city state serves well as an application for the model because of several reasons: The electricity market structure is simple so that no simplifying assumptions need to be made. Furthermore, all required data are publicly available and finally, relevant prices are fairly low so that the outcome is expected to mark a lower bound for profits when compared to other countries.

The remainder of this paper is structured as follows: Section 2 briefly introduces the V2G concept. Section 3 discusses the electricity market in Singapore and sketches the available market data. In Section 4, the price-responsive cost-revenue model is introduced. In Section 5, this model is applied to several scenarios building on data for Singapore which leads to a conclusion on the conditions for the economic viability of V2G. The results are then further investigated in the sensitivity analysis in Section 6. In Sections 7 and 8 findings are discussed and an outlook on future research is given.

\section{The V2G concept}

The V2G concept is depicted in Fig. 1. Energy is produced in power plants and transmitted through maximum, high, medium and low voltage lines to the consumers (e.g. households, enterprises, charging stations, etc.). One type of consumers are EVs which may either use the energy for driving or serve as a shortterm energy storage by charging their batteries in case of power excess or feeding electricity back into the grid in case of power shortages.

The amount of energy and power each individual EV can provide, however, is too low to participate on most electricity markets (in Singapore $1 \mathrm{MW}$ for half an hour is necessary). Meeting these conditions thus requires hundreds to thousands of EVs aggregated to an Electric Vehicle Virtual Power Plant (EV-VPP) [5,13]. This is done by an aggregator who serves as a mediator between the EV owners and the electricity market. The aggregator trades energy at the market and ensures that the EV-VPP is capable of providing the contracted power at all times.

\section{Electricity market in Singapore}

In Singapore, energy is traded at the National Electricity Market Singapore (NEMS) which is controlled by the Energy Market Authority (EMA) [14]. Within the energy market, several submarkets can be distinguished. To explain which of these markets are potentially relevant for V2G, they are briefly discussed in the following sections.

\subsection{Base, central and peak load}

Base load is defined as the lower bound of the daily energy demand. Energy for this load type is produced at the lowest possible production costs considering country-specific governance rules, e.g. regarding security, emissions, etc. Central and peak load constitute the fraction of energy demand which is variable but predictable with high accuracy. Energy for base load can be provided by any kind of power plant while the latter two load types require power generators which can efficiently adapt their output on a medium time scale.

In Singapore, 96\% of electricity generation is provided by gas and oil power plants [15]. Their flexibility allows covering all three load types so that no distinction between base, central and peak load is made. In a result, there is only one price an entity has to pay when buying electricity from a generator, called the Uniform Singapore Energy Price (USEP).

As fluctuations of these load types are low and predictable, they can be efficiently balanced by conventional and inexpensive power

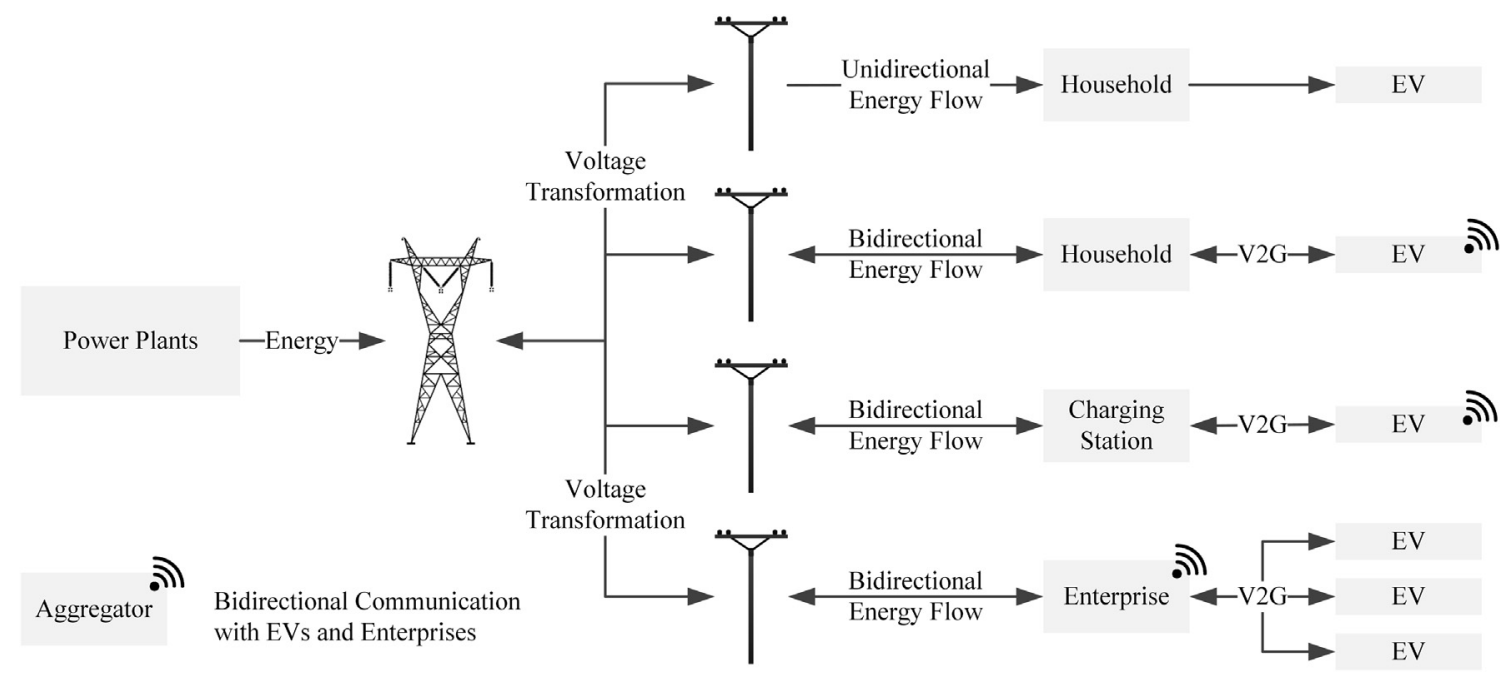

Fig. 1. The V2G concept: energy and communication flows. Adapted from Ref. [9]. 
plants. Therefore, this market is not considered a viable use case for V2G. The USEP will, however, still be relevant for the considerations presented in the remainder of this paper.

\subsection{Ancillary services}

Apart from the predictable variability discussed above, fluctuations occur virtually at every point in time requiring a response within seconds or minutes. They are handled by power stations which provide ancillary services by quickly ramping up their output in case of an under-supply (up-regulation) or curbing their generation if power supply exceeds demand (down-regulation).

Depending upon the response time and the duration of providing ancillary services, it is distinguished between regulation as well as primary, secondary, and contingency reserve [16]. Providers of ancillary services receive a payment on top of the USEP for the dispatched energy when up-regulation is required or a compensation for curbing power generation in the opposite case. These energy payments are called Market Regulation Price (MFP) and Market Reserve Price (MRP) for regulation and reserve, respectively. While there is only one MFP, a distinct MRP is associated with each of the three classes of reserve. Besides these energy payments, many national electricity markets also have a capacity payment which is a reward for only holding power generation potential available rather than actually dispatching energy. This is a major difference from the market in Singapore where this compensation does not exist.

Due to their quick response time, EV batteries are particularly suitable for providing ancillary services. To what degree the provision of any of these four service categories is profitable will be investigated in Section 5.

\subsection{Market data}

The energy market price data used in this study cover the USEP, MFP and all classes of MRP for the entire year 2012 [17]. At the NEMS, all of these prices are adjusted on a half-hourly basis so that all presented calculations build on time series with a 30 min resolution. Additionally, the end-consumer price for electricity, called Electricity Tariff(ET), is used. It mainly consists of energy costs (82\%) as well as transmission costs (17\%) and is subject to quarterly adaptation. To provide a rough overview of these prices and their temporal variance, their average values as well as standard deviations are given in Table 1.

\section{Cost and revenue model}

In this section, the model which is used for investigating the economic viability of V2G is introduced. Total annual profits are calculated from the difference between revenues $R$ and costs $C$

$\Pi=R-C$

which are separately discussed in the following two sections.

Table 1

Key figures of the NEMS price data in 2012.

\begin{tabular}{llllllll}
\hline & ET & USEP & MFP & \multicolumn{3}{l}{ MRP $[S \$ / M W h]$} & \\
\cline { 6 - 8 } & {$[S \$ / M W h]$} & {$[S \$ / M W h]$} & {$[S \$ / M W h]$} & & PR & SR & CR \\
\hline Avg. & 279.3 & 222.49 & 91.53 & 0.33 & 1.37 & 11.40 \\
Std dev. & 5.69 & 112.92 & 40.35 & 2.26 & 4.48 & 64.86 \\
\hline
\end{tabular}

\subsection{Revenues}

The total revenue $R$ is the sum of the revenues made from upregulation and the revenues attained from down-regulation services. For up-regulation the EV is considered a generator. Therefore, energy is sold at the USEP which is topped up by the compensation for ancillary services $p_{\text {Anc. }}$. Depending on the energy market under consideration, $p_{\text {Anc }}$ corresponds to the MFP or the MRP. In this case, the received payment per unit of dispatched energy is

$p_{\uparrow}=\mathrm{USEP}+p_{\text {Anc }}$.

In contrast, in the case of down-regulation the EV acts as a consumer. The owner pays the ET which is discounted by $p_{\text {Anc. }}$. Since the energy purchase costs given by the ET are explicitly accounted for in Section 4.2, the effective payment per unit of energy in this case is therefore simply

$p_{\downarrow}=p_{\text {Anc }}$.

The total annual revenue $R$ is the product of these payments with the respective amounts of purchased and dispatched energy $E_{\uparrow}$ and $E_{\downarrow}$. With $E=\int P(t) \mathrm{d} t$ and both, prices and power being time-dependent, this can be written as

$R=\int_{T_{\uparrow}} p_{\uparrow}(t) P_{\uparrow}(t) \mathrm{d} t+\int_{T_{\downarrow}} p_{\downarrow}(t) P_{\downarrow}(t) \mathrm{d} t$.

In this equation $T_{\uparrow}$ denotes the time when up-regulation is provided while $T_{\downarrow}$ represents the opposite case. As explained in Section 3.2, market prices remain constant during intervals of $\Delta t=30$ minutes. In addition it is assumed that the charging/dispatching power during this time is also kept unchanged. The integral can then be replaced by a sum over the time intervals $i_{\uparrow}$ and $i_{\downarrow}$ at which up- or down-regulation is provided:

$R=\sum_{i_{\uparrow}} p_{\uparrow, i} P_{\uparrow, i} \Delta t+\sum_{i_{\downarrow}} p_{\downarrow, i} P_{\downarrow, i} \Delta t$

\subsection{Costs}

In accordance with Ref. [1], the total annual costs $C_{\mathrm{A}}$ are calculated as the variable costs $c_{\mathrm{var}}=c_{\eta}+c_{\mathrm{D}}$ multiplied by the total annual amount of energy cycled through the battery pack $E_{\mathrm{A}}$, plus annual fixed costs $C_{\mathrm{AF}}$ :

$C_{\mathrm{A}}=E_{\mathrm{A}}\left(c_{\eta}+c_{\mathrm{D}}\right)+C_{\mathrm{AF}}$

In this equation, $c_{\eta}$ denotes the energy purchase costs which, using the charge-discharge efficiency $\eta$, can be written as

$c_{\eta}=\frac{E T}{\eta}$.

The term $c_{D}$ represents the variable battery pack depreciation costs which result from the limited number of possible chargedischarge cycles. Using the purchase costs of a battery pack $C_{\mathrm{Bat}}$ teryPack and the total possible energy throughput $E_{\text {Lifetime, this turns }}$ into

$c_{\mathrm{D}}=\frac{C_{\text {BatteryPack }}}{E_{\text {Lifetime }}}$.

The quantity of energy which can be cycled through a battery pack until it fails to meet its specific performance criteria is given by the capacity $Q_{\text {BatteryPack }}$ multiplied by the depth of discharge 
(DOD) and the maximum number of cycles $Z$ possible at a certain DOD:

$E_{\text {Lifetime }}=Z \cdot \mathrm{DOD} \cdot Q_{\text {BatteryPack }} \cdot$

One cycle in this context is understood as discharging the battery from an initial state of charge (SOC) by a certain DOD and subsequently recharging it to the initial SOC; the Ah throughput per cycle therefore depends upon the corresponding DOD. The cycle stability $Z$ is a quantity which depends on a large number of parameters such as $C$-rate, DOD, temperature, humidity and time and which strongly varies among different battery chemistries [18]. It is therefore not possible to reliably model the cyclic lifetime so that many studies simply assume a fixed number for $Z[7,9,11,12]$. To at least account for the important dependency of battery lifetime from the DOD, calculations in this paper are based on a functional relation between $Z$ and DOD. This relationship results from a fit to a series of measurement data and is adopted from Ref. [19]:

$Z(\mathrm{DOD})=\left(\frac{145.71}{\mathrm{DOD}}\right)^{\frac{1}{0.6844}}$

The last term of Eq. (6) $C_{\mathrm{AF}}$ denotes the fixed costs which account for the investment in equipment required in making an EV suitable for V2G. To annualize and discount the fixed costs, it is written as

$C_{\mathrm{AF}}=C_{\mathrm{C}} \frac{d}{1-(1+d)^{-n}}$

with $C_{C}$ being the total capital costs, $d$ the discount rate and $n$ the number of years until the investment is depreciated.

With these considerations, the total annual costs can finally be rewritten as.

$C_{\mathrm{A}}=E_{\mathrm{A}}\left(\frac{E T}{\eta}+\frac{C_{\text {BatteryPack }}}{Z(\mathrm{DOD}) \cdot \mathrm{DOD} \cdot Q_{\text {BatteryPack }}}\right)+C_{\mathrm{C}} \frac{d}{1-(1+d)^{-n}}$.

\subsection{Price-responsive charging/dispatching strategy}

To avoid financial losses, the decision on whether to provide ancillary services should depend on instantaneous electricity prices. To achieve profitability, revenues generated in a certain time period must be greater than the corresponding variable costs. In the presented model, this is considered by setting the charging/dispatching power to 0 in case the variable costs $c_{\mathrm{var}}=c_{\eta}+c_{\mathrm{D}}$ are equal or greater than the compensation payment:

$P_{\uparrow / \downarrow, i}=\left\{\begin{array}{ll}P, & p_{\uparrow / \downarrow}\left(t_{i}\right)>c_{\mathrm{var}} \\ 0, & p_{\uparrow / \downarrow}\left(t_{i}\right) \leq c_{\mathrm{var}}\end{array}\right.$.

Employing this method emulates a price-responsive charging/ dispatching strategy which only allows market participation at times when profits are expected.

\section{Assessment of V2G profitability in different scenarios}

In this section, the cost and revenue model is applied to the electricity market data described in Section 3. Initially, a basic scenario is investigated where an EV provides ancillary services during $24 \mathrm{~h}$ a day without obeying the condition given by Eq. (13). A second scenario addresses a setup which also assumes a gridconnection of $24 \mathrm{~h}$ a day, but in this case the price-responsive strategy is employed. Finally, a set of scenarios is presented that take the limited vehicle availability into account which is given by realistic mobility patterns in Singapore.
In all cases, a battery pack capacity of $20 \mathrm{kWh}$ is assumed. This is in accordance with the battery dimensions of the Nissan Leaf (24 kWh) and the Mitsubishi i-MiEV (16 kWh). The battery pack replacement costs are set to $S \$^{2} 770$ per $\mathrm{kWh}$ which reflects present prices according to Refs. [20] and [21]. Equipment for enabling EVs to provide V2G services is expected to yield fixed costs of only a few hundred S\$. These costs are negligibly low when prorated over the whole lifetime of the battery pack and are therefore not considered in the remainder of this paper. In accordance with findings from the literature, the energy efficiency of a charge-discharge process is set to $\eta=0.73$ [1]. Charging and discharging power are both set to $P=2 \mathrm{~kW}$ which corresponds to a C-rate of 0.1 and which presumes that the product of current and voltage is kept constant. This is realistic for small DOD and when extreme values of the SOC close to $0 \%$ or $100 \%$ are rare. By neglecting the capacity fade over time, a fixed time interval of $30 \mathrm{~min}$ then corresponds to a DOD of $5 \%$ or a throughput of 270 Ah respectively. The chosen value for $P$ is believed to be a sensible compromise between maximizing revenues on the one hand and a reasonable battery depletion and depreciation on the other one. As both positive and negative regulation alternate at a high frequency, it can be assumed that an EV can offer up-regulation in one interval and down-regulation in the following one. This ensures that the targeted DOD is not exceeded and that the degree of battery depletion remains predictable. Since several of the mentioned numbers broadly disperse in reality and are expected to change over time, these parameters are varied as part of the sensitivity analysis presented in Section 6 .

The quantities which are repeatedly discussed in the following sections are the ratio of profitable periods as well as annual values for revenues, variable costs and profits. Given the fixed time intervals of $30 \mathrm{~min}$, a day consists of 48 periods. The ratio of profitable periods denotes the annual average fraction of these time intervals which is profitable according to Eq. (13). As fixed costs calculated by Eq. (11) are neglected, profits simply result from the difference between revenues and variable costs. To highlight the relevance of costs arising from battery degradation and imperfect chargedischarge efficiency $\eta$, the revenues are already reduced by the electricity purchase costs given by the ET.

\subsection{Basic scenario}

The simplest possible scenario is to consider an EV to be gridconnected 24 h per day, 365 days a year. Although this assumption is fairly unrealistic, it allows a first estimate on the economic attractiveness of the different market types introduced in Section 3.

Table 2 depicts revenues and profits for one EV in the regulation market as well as in the three reserve energy markets. The results show that even by neglecting variable costs, revenues are positive in the regulation market only. Negative revenues occur because in many cases the ET at which electricity is purchased exceeds the received payments given by the sum of the USEP and the ancillary service compensation.

Battery depreciation and energy dissipation result in additional costs that ultimately lead to losses in all four cases. To illustrate this, Fig. 2 exemplarily shows revenues and variable costs for one week in March 2012. While revenues fluctuate due to time-dependent prices, variable costs are constant. In most of the periods, variable costs are higher than revenues which results in losses. A priceresponsive charging/dispatching strategy which prohibits market participation during unprofitable periods is therefore a necessary condition for making V2G profitable.

\footnotetext{
${ }^{2}$ S\$ 1 equals 0.8 USD (5 November 2013).
} 
Table 2

Annual profits in different electricity markets regarding the basic scenario.

\begin{tabular}{llc}
\hline Market & Revenues [S\$/Year] & Profits [S\$/Year] \\
\hline Regulation & 1109 & -985 \\
Reserve, primary & -491 & -2585 \\
Reserve, secondary & -466 & -2560 \\
Reserve, contingency & -226 & -2320 \\
\hline
\end{tabular}

Variable costs [S\$/year]: 2094.

\subsection{Price-responsive scenario}

In this section, the implications of the price-responsive charging/dispatching strategy are investigated. The assumption of an availability of $24 \mathrm{~h}$ at 365 days a year is maintained, however, it is ensured that ancillary services are only provided during profitable time periods.

In Table 3, revenues, costs, and profits for one EV in the regulation and the three reserve energy markets are depicted. In addition, the fraction of profitable time periods is given. It is shown that profits are attained in all four cases. The highest profits are achieved in the regulation market where this strategy yields an annual return of $S \$ 130$ by providing ancillary services in about $12 \%$ of all periods. In the primary and secondary reserve market profits are negligibly low. With $S \$ 115$, profits in the contingency market are in the same range as in the regulation market. Nevertheless, only a low share of time periods is profitable in this case. This means that returns are only the result of a small number of time intervals with high prices. Assuming cases where EVs are only grid-connected at certain times, the probability of missing these few intervals is high. Given these more realistic assumptions, expected profits in the contingency market are therefore negligibly low. As a result of these findings, only the regulation market will be considered in the remainder of this paper.

\subsection{Mobility pattern based scenarios}

While the previous results were based on the assumption of uninterrupted grid-connection, results in this section are built on more realistic estimations on vehicle availability. This is achieved by using typical mobility patterns of Singapore residents adapted from Ref. [22]. These patterns describe the trips various groups of people undertake on different days of the week and represent about $90 \%$ of the population. In particular, the data specify the start and end time of a trip as well as the type of destination categorized by home $(\mathrm{H})$, work $(\mathrm{W})$ and leisure $(\mathrm{L})$. This reveals information on the time windows at which EVs can be connected to the grid

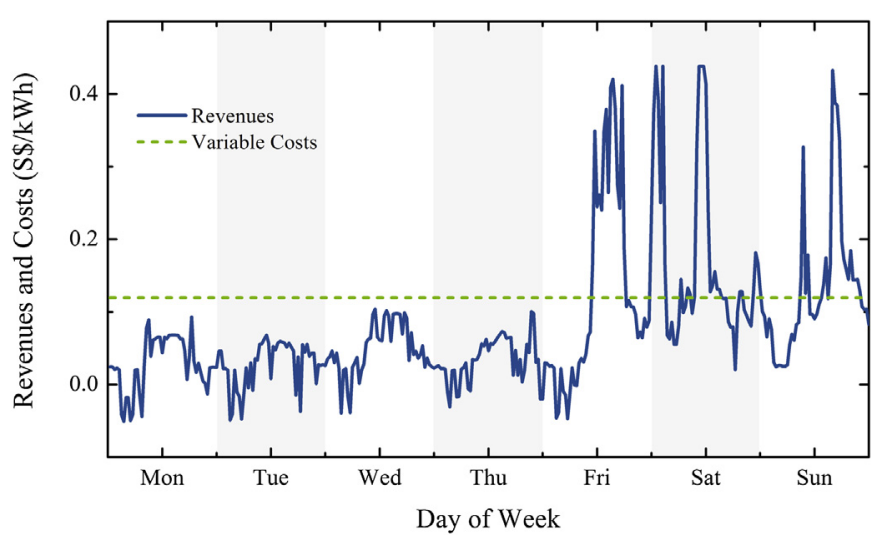

Fig. 2. Exemplary illustration of revenues and variable costs for a week in March 2012.
Table 3

Annual profits in different electricity markets regarding the price-responsive scenario.

\begin{tabular}{lllll}
\hline Market & $\begin{array}{l}\text { Revenues } \\
\text { [S\$/year] }\end{array}$ & $\begin{array}{l}\text { Var. costs } \\
\text { [S\$/year] }\end{array}$ & $\begin{array}{l}\text { Profits } \\
\text { [S\$/year] }\end{array}$ & $\begin{array}{l}\text { Profitable } \\
\text { periods [\%] }\end{array}$ \\
\hline Regulation & 384 & 254 & 130 & 12 \\
Reserve, primary & 43 & 19 & 24 & 0.9 \\
Reserve, secondary & 47 & 20 & 27 & 1.0 \\
Reserve, contingency & 174 & 59 & 115 & 2.8 \\
\hline
\end{tabular}

depending upon the availability of charging stations at the various types of destinations. The mobility patterns should not be confused with driving cycles such as the New European Driving Cycle (NEDC) which describe standardized velocity profiles for fuel consumption and emission measurements.

As indicated in Table 4, four different patterns for weekdays and three patterns for Sundays were used. Due to the lack of data, the Saturday pattern was generated from a weighted combination of week- and Sundays. Specific timings and durations were part of the calculations but are not explicitly stated in the table.

Using the price-responsive charging/dispatching approach, profits for each pattern were calculated. In Table 5 it can be seen that annual profits made from Monday to Friday do not exceed S\$ 71 , Saturday returns contribute $\$ \$ 22$ and Sunday profits reach a maximum of $S \$ 28$. In a best case scenario, annual profits therefore sum up to $S \$ 121$ while in a worst case $S \$ 98$ is possible. By weighting all profiles according to their share in the population, profits for an average Singapore resident amount to S\$ 111 which is not far below the maximum value of $\$ \$ 130$ obtained in the previous section.

It has to be noted that achieving these results requires V2Gcapable charging stations at every stop. Since this is fairly unlikely, the implications of a grid-connection solely at home were also investigated. To obtain an upper bound for profits in this case, the calculation was based on the profiles W2 and SU3. The results in Table 6 show that annual profits drop down to S\$ 21 and the number of profitable periods is reduced to less than $2 \%$. The reason for this significant decrease is the low compensation for ancillary services during off-peak hours which typically are the times when vehicles are parked at home. This is an important result because it shows that the profitability of V2G is very low at times when the number of grid-connected EVs is at its maximum.

\section{Sensitivity analysis}

According to the results presented in the previous section, V2G profits are unlikely to be high enough to encourage EV owners to provide ancillary services. Many of the involved parameters, however, are subject to uncertainties and are also expected to change over time. Therefore, in the following sensitivity analysis the

Table 4

Mobility patterns of Singapore residents.

\begin{tabular}{llll}
\hline $\begin{array}{l}\text { Mobility } \\
\text { pattern }\end{array}$ & $\begin{array}{l}\text { Day of } \\
\text { week }\end{array}$ & $\begin{array}{l}\text { Mobility pattern } \\
\text { description }\end{array}$ & $\begin{array}{l}\text { Share of profile } \\
\text { in population [\%] }\end{array}$ \\
\hline W1 & Mon-Fri & H-W-L-H & 23 \\
W2 & Mon-Fri & H-W-H & 23 \\
W3 & Mon-Fri & H-W-L-W-L-H & 23 \\
W4 & Mon-Fri & H-W-L-W-H & 23 \\
SA1 & Sat & a & 90 \\
SU1 & Sun & H-L-L-L-H & 20 \\
SU2 & Sun & H-L-H-L-H & 20 \\
SU3 & Sun & H & 60 \\
\hline
\end{tabular}

${ }^{a}$ Weighted combination of weekday and Sunday mobility patterns. 
Table 5

Profits resulting from different mobility patterns.

\begin{tabular}{lllll}
\hline $\begin{array}{l}\text { Mobility } \\
\text { pattern }\end{array}$ & $\begin{array}{l}\text { Revenues } \\
\text { [S\$/year] }\end{array}$ & $\begin{array}{l}\text { Var. costs } \\
\text { [S\$/year] }\end{array}$ & $\begin{array}{l}\text { Profits } \\
\text { [S\$year] }\end{array}$ & $\begin{array}{l}\text { Profitable } \\
\text { periods [\%] }\end{array}$ \\
\hline W1 & 223 & 153 & 70 & 10.2 \\
W2 & 230 & 159 & 71 & 10.6 \\
W3 & 177 & 122 & 55 & 8.1 \\
W4 & 189 & 132 & 57 & 8.8 \\
SA1 & 60 & 38 & 22 & 10.5 \\
SU1 & 51 & 29 & 22 & 9.6 \\
SU2 & 50 & 29 & 21 & 9.6 \\
SU3 & 65 & 37 & 28 & 12.3 \\
\hline
\end{tabular}

Revenues, costs and profits for W1 to W4 result from the sum of all weekdays (261 days), while the corresponding numbers for SA1 and SU1 to SU3 account for all Saturdays (52 days) and Sundays (53 days) respectively.

dependence of profits from the most important parameters is presented. All investigations in this section are based on the priceresponsive scenario introduced in Section 5.2.

\subsection{Charging/Discharging power}

A parameter that can be easily adapted in reality is the charging/ discharging power $P$. With a higher $P$, more energy can be sold or purchased which increases revenues per time period. With more energy being cycled, energy losses, however, also increase which in turn causes higher variable costs. Since the duration of dispatch intervals remains unchanged at $30 \mathrm{~min}$, a greater charging power also implies a deeper DOD which increases battery degradation costs. As a result, higher power does not necessarily yield growing profits. Additionally, the design of electrical components such as inverter, power cables and the distribution box as well as the technical specifications of the charging station depend on the maximum connection power. In principle, a higher $P$ would therefore also imply higher investment costs. In Section 5 it was assumed that the existing charging components make an EV inherently V2G ready so that the costs of these components do not need to be attributed to V2G. In case an EV would be upgraded specifically for the purpose of providing higher V2G power, the related costs would, however, have to be explicitly taken into account as fixed costs in Eq. (12). As this investment would be in the range of several thousand $\$ \$$, it is assumed that such an upgrade would not be performed specifically for V2G. Hence, only EVs with existing fast charging equipment could be considered for providing V2G services at a higher power. In accordance with the assumptions on fixed costs made for the previous sections, in this case, the related costs do not have to be attributed to V2G.

The results of the power variation are shown in Table 7 and Fig. 3. It is observed that both revenues and profits increase with $P$. At $2 \mathrm{~kW}$ the number of profitable periods has, however, dropped to less than $10 \%$ already. This means that in the domain of higher $P$, profits primarily result from a few time windows with high electricity prices. According to Table 1, these price fluctuations mainly occur within the USEP which exhibits a significant variance with maximum values of up to $S \$ 4000$. Given that in reality EVs are only grid-connected during a certain part of the day, the probability of missing these few profitable periods is considerably high.

Table 6

Annual profits from offering V2G services solely at home.

\begin{tabular}{lllll}
\hline $\begin{array}{l}\text { Mobility } \\
\text { pattern }\end{array}$ & $\begin{array}{l}\text { Revenues } \\
\text { [S\$/year] }\end{array}$ & $\begin{array}{l}\text { Var. costs } \\
\text { [S\$/year] }\end{array}$ & $\begin{array}{l}\text { Profits } \\
\text { [S\$/year] }\end{array}$ & $\begin{array}{l}\text { Profitable } \\
\text { periods [\%] }\end{array}$ \\
\hline W2 & 48 & 36 & 12 & 1.7 \\
SA1 & 12 & 9 & 3 & 0.5 \\
SU3 & 17 & 11 & 6 & 0.9 \\
\hline
\end{tabular}

Table 7

Revenues, costs and profits when varying charging/discharging power.

\begin{tabular}{llllll}
\hline $\begin{array}{l}\text { Power } \\
{[\mathrm{kW}]}\end{array}$ & $\begin{array}{l}\text { Revenue } \\
{[\text { S\$/year] }}\end{array}$ & $\begin{array}{l}\text { Var. Costs } \\
{[\text { S\$/period] }}\end{array}$ & $\begin{array}{l}\text { Var. Costs } \\
{[S \$ / \text { year] }}\end{array}$ & $\begin{array}{l}\text { Profits } \\
{[S \$ / \text { year] }}\end{array}$ & $\begin{array}{l}\text { Profitable } \\
\text { periods [\%] }\end{array}$ \\
\hline 1 & 286 & 0.0505 & 194 & 92 & 22 \\
2 & 384 & 0.1195 & 254 & 130 & 12 \\
3 & 436 & 0.2002 & 277 & 159 & 7.9 \\
4 & 457 & 0.2901 & 272 & 185 & 5.3 \\
5 & 461 & 0.3880 & 250 & 212 & 3.7 \\
6 & 499 & 0.4928 & 261 & 238 & 3.0 \\
7 & 557 & 0.6040 & 294 & 263 & 2.8 \\
8 & 609 & 0.7210 & 323 & 286 & 2.6 \\
9 & 657 & 0.8435 & 349 & 308 & 2.4 \\
10 & 705 & 0.9710 & 376 & 329 & 2.2 \\
11 & 752 & 1.1033 & 404 & 348 & 2.1 \\
12 & 801 & 1.2402 & 434 & 367 & 2.0 \\
13 & 851 & 1.3814 & 467 & 384 & 1.9 \\
14 & 899 & 1.5269 & 499 & 400 & 1.9 \\
15 & 938 & 1.6763 & 521 & 417 & 1.8 \\
\hline
\end{tabular}

\subsection{Efficiency factor}

With the increasing maturity of battery technology and the development of super capacitors, the charging/discharging efficiency $\eta$ is expected to undergo further improvements. The reduced energy dissipation will therefore result in decreased variable costs. This is expected to increase profits per period on the one hand and increase the number of profitable periods on the other. To illustrate this dependency, profits as a function of $\eta$ are shown in Table 8 and Fig. 4.

As expected, an efficiency increase leads to decrease in variable costs per period and growth in the number of profitable periods. While the absolute profit increase is fairly low for $\eta<0.8$, a more significant rise is observed at higher efficiencies. As shown in Fig. 4, this correlates with an equally strong increase in the number of profitable periods. This results from the distribution of electricity prices which is shown in Fig. 5. It can be observed that the upper 3\% of prices (Region 3) exhibit a high variance with maximum values of up to $\mathrm{S} \$ 4000$ in case of the USEP. This domain is followed by a broad plateau that makes up about $83 \%$ of all time periods (Region 2). Finally, $14 \%$ of the time intervals exhibit low prices with again higher fluctuations (Region 1 ). In case of efficiencies below 0.6 , only the periods of Region 3 are profitable. By further increasing $\eta$, the intervals belonging to the plateau of Region 2 also become economically viable. In this area, a slight increase in efficiency significantly raises the number of profitable time periods leading to a considerable profit increase. Current batteries with cycle efficiencies slightly below 0.8 are therefore just at the lower edge of a

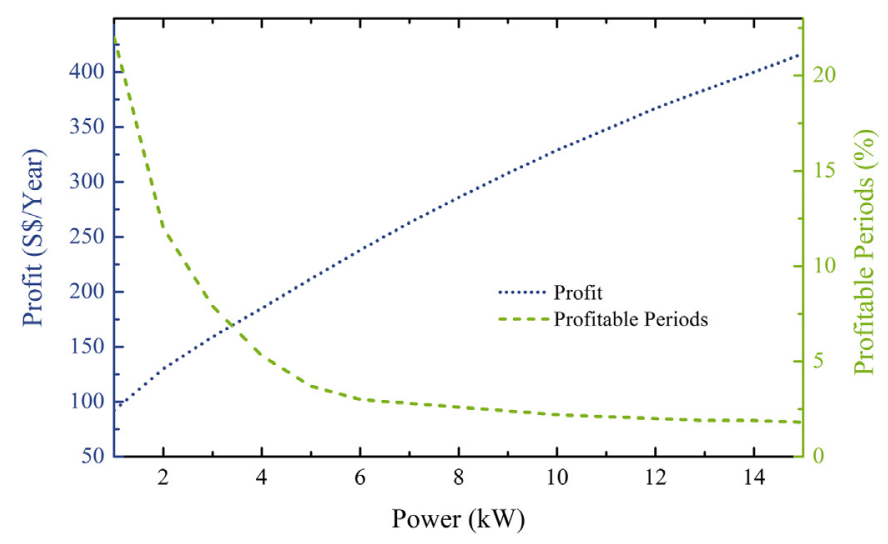

Fig. 3. Profits as a function of charging/discharging power. 
Table 8

Revenues, costs and profits when varying the efficiency.

\begin{tabular}{lllccc}
\hline Efficiency & $\begin{array}{l}\text { Revenues } \\
\text { [S\$/year] }\end{array}$ & $\begin{array}{l}\text { Var. costs } \\
\text { [S\$/period] }\end{array}$ & $\begin{array}{l}\text { Var. costs } \\
\text { [S\$/year] }\end{array}$ & $\begin{array}{l}\text { Profits } \\
\text { [S\$/year] }\end{array}$ & $\begin{array}{l}\text { Profitable } \\
\text { periods [\%] }\end{array}$ \\
\hline 0.1 & 23 & 1.3247 & 15 & 8 & 0.1 \\
0.2 & 25 & 0.6265 & 8 & 17 & 0.1 \\
0.3 & 54 & 0.3937 & 31 & 23 & 0.4 \\
0.4 & 102 & 0.2773 & 61 & 41 & 1.3 \\
0.5 & 134 & 0.2075 & 73 & 61 & 2.0 \\
0.6 & 172 & 0.1610 & 91 & 81 & 3.2 \\
0.7 & 327 & 0.1277 & 213 & 114 & 9.5 \\
0.8 & 551 & 0.1028 & 374 & 177 & 21 \\
0.9 & 736 & 0.0834 & 469 & 267 & 32 \\
1.0 & 846 & 0.0679 & 480 & 366 & 40 \\
0.73 & 384 & 0.1195 & 254 & 130 & 12 \\
\hline
\end{tabular}

region where incremental technology improvements lead to significant relative increases of financial returns. Nevertheless, even with $\eta=1,60 \%$ of the time periods remain unused due to the remaining battery depreciation costs. Efficiency increases alone will hence not be sufficient to make V2G economically attractive.

\subsection{Battery model}

Another crucial factor for the economic viability of V2G is the battery model. To accommodate this, investigations of variable and fixed battery pack costs are conducted in this section.

As discussed in Section 4, the cyclic lifetime of a battery strongly depends on a large number of parameters and cannot easily be expressed in a simple equation. Therefore, the cyclic lifetime given by Eq. (10) was scaled between a factor of 0.1 and 100,000 to investigate possible effects on profits. Even though this is a fairly broad range, different cell chemistries and charging/discharging strategies realistically permit cyclic lifetime factors between 0.1 and 10. The high cyclic lifetime values at the upper bound of this scale where chosen to demonstrate the limit case of diminishing battery depreciation costs. Equally, it indicates a lower cost limit that could be achieved by further improving battery technology or in case super capacitors would reach sufficiently high energy densities for being applied in EVs.

The results of this variation are listed in Table 9 and graphically illustrated in Fig. 6. The variable costs are disproportionately low dependent on the cyclic lifetime. Although profits scale linearly with the cyclic lifetime, the amount of used periods already drops below $10 \%$ when scaling the cyclic lifetime by a factor of approximately 0.9 . In case of an efficiency factor smaller than 0.9 only few periods with an extremely high compensation remain profitable.

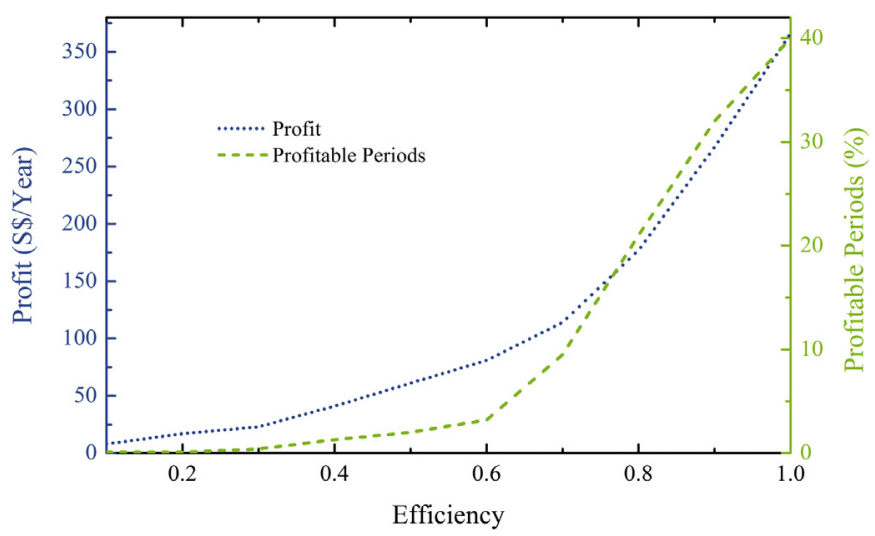

Fig. 4. Profits and profitable periods as a function of the efficiency factor.

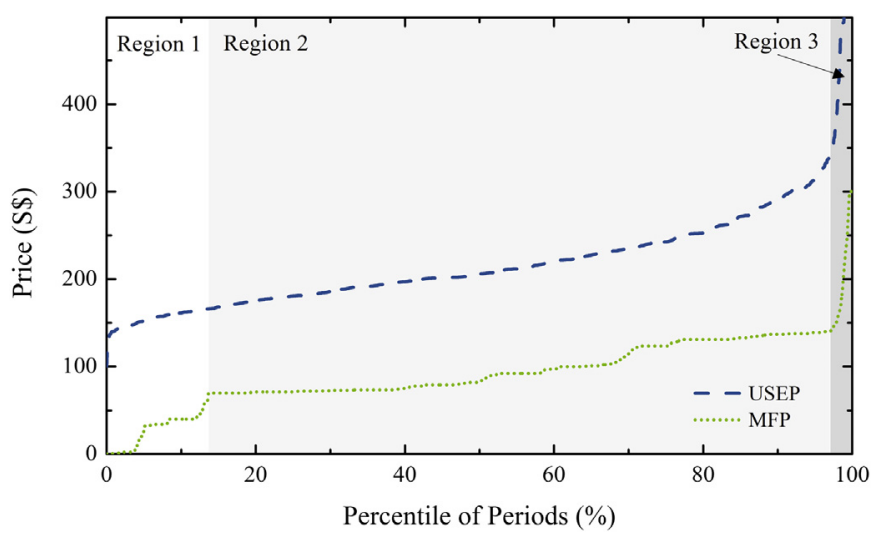

Fig. 5. Distribution of USEP and MFP.

The maximum profit of $\mathrm{S} \$ 497$ at $52 \%$ of profitable periods is achieved as the cyclic lifetime goes to infinity. The remaining variable costs of $\mathrm{S} \$ 0.05$ per period result from the energy losses investigated in the previous section. To further increase profits, other parameters have to be modified.

Varying the battery pack price has the same effect on the variable costs as changing the cyclic lifetime. Cutting fixed battery pack costs in half thus results in the same profits as doubling the cyclic lifetime. Therefore, diminishing battery pack costs and increasing cycle stability yield equal results so that an explicit sensitivity analysis of this parameter can be omitted.

\subsection{Prices}

As electricity prices are volatile, it is important to quantify the dependency of profits on variations of prices for buying and selling energy. This was separately done for the ET, USEP, and MFP which were scaled in a range from 0.5 to 1.5 . The results of this variation are shown in Table 10 and graphically illustrated in Fig. 7.

It can be seen that a rising ET causes a disproportionately high decrease of profits. In contrast, the lower the ET the higher the share of periods in which V2G services can be offered. On the contrary, it is observed that a raise of either the USEP or the MFP leads to a disproportionately high increase of profits as well as the amount of profitable periods.

With an ET price factor greater than 1 or either an MFP or USEP price factor smaller than 1 the amount of profitable periods drops below $10 \%$. When moving the price factor further in these directions, profits are mostly generated during periods where the sum of USEP

Table 9

Costs and profits when varying the cyclic lifetime.

\begin{tabular}{llllll}
\hline $\begin{array}{l}\text { Lifetime } \\
\text { factor }\end{array}$ & $\begin{array}{l}\text { Revenues } \\
\text { [S\$/year] }\end{array}$ & $\begin{array}{l}\text { Var. Costs } \\
\text { [S\$/period] }\end{array}$ & $\begin{array}{l}\text { Var. Costs } \\
\text { [S\$/year] }\end{array}$ & $\begin{array}{l}\text { Profits } \\
\text { [S\$/year] }\end{array}$ & $\begin{array}{l}\text { Profitable } \\
\text { periods [\%] }\end{array}$ \\
\hline 0.1 & 25 & 0.7303 & 9 & 16 & 0.1 \\
0.2 & 55 & 0.3910 & 32 & 23 & 0.5 \\
0.3 & 102 & 0.2779 & 61 & 41 & 1.3 \\
0.4 & 126 & 0.2213 & 70 & 56 & 1.8 \\
0.5 & 146 & 0.1874 & 78 & 68 & 2.4 \\
0.6 & 165 & 0.1648 & 86 & 79 & 3.0 \\
0.7 & 207 & 0.1486 & 118 & 89 & 4.5 \\
0.8 & 276 & 0.1365 & 174 & 102 & 7.3 \\
0.9 & 330 & 0.1271 & 214 & 116 & 9.6 \\
1 & 384 & 0.1195 & 254 & 130 & 12 \\
10 & 917 & 0.0584 & 479 & 438 & 47 \\
100 & 965 & 0.0523 & 475 & 490 & 52 \\
10,000 & 970 & 0.0517 & 474 & 497 & 52 \\
100,000 & 970 & 0.0517 & 474 & 497 & 52 \\
\hline
\end{tabular}

The number of cycles for the factor of 1 is 115,379 . 


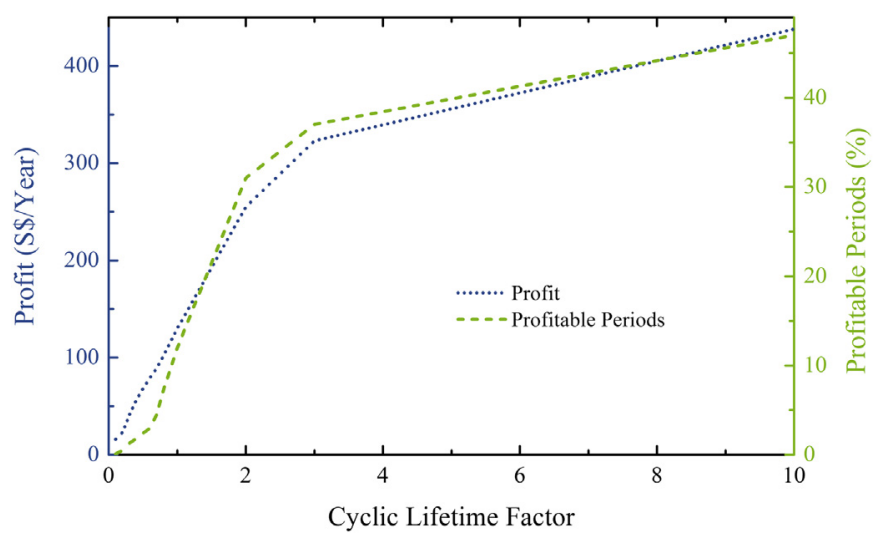

Fig. 6. Profits as a function of the cyclic lifetime.

and MFP is considerably high. Not being constantly connected to the grid poses the greater likelihood of missing a fraction of those periods, potentially resulting in significantly reduced profits.

\section{Discussion}

This section summarizes and evaluates the findings of applying the presented price-responsive cost and revenue model to the electricity market data of Singapore. To show the relevance of these results for other countries, a qualitative discussion of the characteristics of the Singaporean market compared to other national markets is given. Furthermore, the benefits of the proposed strategy on power grid stability as well as the limitations of the applied cost and revenue model are examined.

\subsection{Profitability of V2G}

The results in Section 5 show that given present market conditions and realistic technical parameters, a price-responsive charging/dispatching strategy is a necessary condition for the profitability of V2G. By employing this strategy, a maximum annual profit of $S \$ 130$ could be achieved at the regulation market. This, however, requires an EV to be grid-connected at all times. Considering more realistic mobility patterns with lower vehicle availability, profits drop to $S \$ 98$ per year. In the most likely case in which EVs are only grid-connected at home, profits further decrease to only $S \$ 21$. This leads to the conclusion that given the conditions defined in this paper, V2G is unlikely to be a profitable concept for EV owners in Singapore.

Table 10

Costs and profits when varying the ET, USEP and MFP.

\begin{tabular}{llllll}
\hline Price & $\begin{array}{l}\text { Price } \\
\text { factor }\end{array}$ & $\begin{array}{l}\text { Revenues } \\
\text { [S\$/year] }\end{array}$ & $\begin{array}{l}\text { Var. Costs } \\
\text { [S\$/year] }\end{array}$ & $\begin{array}{l}\text { Profits } \\
\text { [S\$/year] }\end{array}$ & $\begin{array}{l}\text { Profitable } \\
\text { periods [\%] }\end{array}$ \\
\hline ET & 0.5 & 1647 & 1130 & 516 & 54 \\
& 0.75 & 920 & 659 & 261 & 31 \\
& 1 & 384 & 254 & 130 & 12 \\
& 1.25 & 164 & 78 & 85 & 3.7 \\
MFP & 1.5 & 117 & 49 & 68 & 2.3 \\
& 0.5 & 76 & 37 & 39 & 1.8 \\
& 0.75 & 136 & 68 & 68 & 3.2 \\
& 1 & 384 & 254 & 130 & 12 \\
& 1.25 & 835 & 572 & 263 & 27 \\
USEP & 1.5 & 1374 & 898 & 477 & 43 \\
& 0.5 & 103 & 48 & 55 & 2.3 \\
& 0.75 & 161 & 83 & 79 & 3.9 \\
& 1 & 384 & 254 & 130 & 12 \\
& 1.25 & 853 & 598 & 254 & 28 \\
& 1.5 & 1243 & 793 & 450 & 38 \\
\hline
\end{tabular}

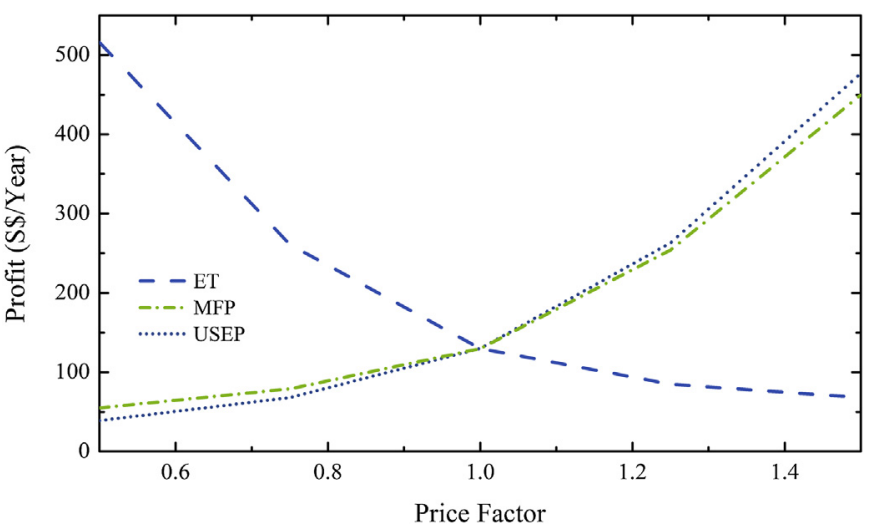

Fig. 7. Profits as a function of the ET, MFP and USEP.

According to the sensitivity analysis, adaptations of certain parameters may, however, improve the economic viability of V2G. The first parameter under consideration was the charging-discharging power. With an increase of power, revenues grow faster than the corresponding variable costs. This may yield annual profits of several hundred S\$. It, however, comes at the cost of decreasing the amount of profitable periods to less than $2 \%$. Assuming realistic mobility patterns, chances of missing those periods are high which would ultimately lead to a decrease in expected profits. Furthermore, high power connectivity requires the availability of fast charging technology both in the EV as well as in the charging station which would cause additional investment costs in the range of several thousand S\$. A simple increase of power can therefore not be considered a driver for higher profitability. As the second parameter, the charging-discharging efficiency was investigated. A higher efficiency yields a disproportionately high increase in profitable periods and therefore also in profits. Given the electricity price structure in Singapore, this profit increase is most pronounced at efficiencies above 0.8 where incremental improvements of technology lead to a significant relative increase in returns. Another parameter which has a major influence on profits was found to be the cyclic lifetime of the battery, of which a variation in a realistic range could result in profits of up to $\$ \$ 500$. This profit increase could equally be achieved by a drop in battery prices whose variation technically has the same effect as varying cyclic lifetimes. On the electricity market side, increasing the MFP or the USEP or decreasing the ET respectively yields a proportionately high increase in profitable periods and therefore in profits. Furthermore, a shift of high price periods into the time periods when EVs are more likely to be grid-connected could increase expected profits. This could possibly be the result of higher shares of wind energy which typically generates higher power during the night when most EVs are available.

As a result, even though the considerations in Section 5 arrive at the conclusion that expected profits are fairly low, the sensitivity analysis shows that both technological improvements as well as different price structures could have a significant effect on the profitability of V2G.

\subsection{Applicability to other national markets}

As the model presented in this paper is applied to data for Singapore, the question arises whether the results are applicable to other markets. Since a quantitative conclusion would require the analysis of price data, this is only discussed in a qualitative way.

One important difference between Singapore and a number of other markets is the missing capacity payment. This payment, 
however, is an important revenue stream in countries such as Germany and the US where it was found to be the major source of profits $[1,9]$.

On the contrary, the fiscal framework for V2G appears to be more beneficial in Singapore than elsewhere. The ET almost entirely consists of generation and transmission costs without any taxes added. This is in contrast to other markets where an EV owner has to pay consumption taxes on the electricity price even if the energy may just be bought for the purpose of feeding it back into the grid. A different taxation policy could therefore yield higher profits in these countries while there is little potential for improvements in Singapore.

It is concluded that Singapore most likely marks a lower bound for $V 2 G$ related profits. It is therefore assumed that the priceresponsive charging/dispatching strategy combined with the returns from a capacity payment could yield significantly greater profits in other markets.

\subsection{Benefits for power grid stability}

From the technical perspective of stabilizing the power grid, the price-responsive strategy is in principle equivalent to the simple approach of continuously providing V2G services. Since nonprofitable periods are omitted, the overall contribution of V2G to stabilizing the power grid would, however, be reduced compared to the basic scenario in Section 5.1. At first glance, this may be considered a drawback because other entities need to satisfy the demand for ancillary services during these times. In the basic scenario, the profitability of V2G, however, is subject to randomness and financial losses need to be expected. Under these conditions it would be unlikely that V2G would achieve a sufficiently broad acceptance among EV owners at all. This implies that its potential for improving power grid stability would remain largely unutilized. A smart charging/dispatching approach which ensures profitability as presented here is therefore crucial for creating appropriate framework conditions for the practical employment of V2G.

\subsection{Model limitations}

One of the main limitations of the considerations presented in this paper is the difficulty of determining battery depreciation costs. Models that allow reliable conclusions on battery ageing depending on energy throughput, DOD and power are not available beyond a threshold of 500 to 1000 cycles. Consequently, the assumption of a reasonable charging/discharging power of $2 \mathrm{~kW}$ needs further support.

A drawback regarding the electricity market data is that information on regulation and reserve energy dispatch is not available in Singapore. As a result, no conclusion on the market size can be made. Since quick market saturation with a comparably low number of vehicles was shown to be an issue in several other countries $[6,8]$, this is an important question to address.

\section{Conclusion and outlook}

This paper describes a dynamic model for calculating the profits EV owners could attain in Singapore by providing ancillary services to the power system. The calculation builds on temporally resolved electricity market data and emulates an intelligent charging/dispatching strategy. This strategy aims at avoiding financial losses by only providing ancillary services at times when expected revenues are greater than costs. Using this model, profits for an idealized scenario as well as for several realistic mobility patterns are quantified.
Compared to the most commonly discussed scenario in which an EV continuously provides V2G services whenever gridconnected, the presented price-responsive charging/dispatching strategy turns a maximum loss of S\$ 1000 into a S\$ 130 profit. By applying realistic mobility patterns, this value decreases to $S \$ 21$ in the worst case. The investigation therefore leads to the conclusion that given the conditions defined in this paper, V2G is unlikely to be a profitable concept for EV owners in Singapore. The sensitivity analysis, however, shows that technological improvements could further increase profits. Since the price-responsive charging/dispatching strategy has a significantly positive impact on the economic viability of $\mathrm{V} 2 \mathrm{G}$, other energy markets with more favorable market conditions should be investigated accordingly.

Future work will build on an agent-based traffic simulation coupled with a power system simulation $[23,24]$. This will allow investigating the dynamic interaction between complex mobility and charging patterns with the power system. By including more sophisticated battery models, the implications of different charging strategies can be assessed more effectively. Part of these investigations will also be a quantitative comparison of different national markets. The overall goal of this research will be to systematically explore the scenario space consisting of a large variety of technological and economic framework conditions to identify configurations that are most favorable for the application of V2G.

\section{Acknowledgments}

This work was financially supported by the Singapore National Research Foundation (NRF) under its Campus for Research Excellence and Technological Enterprise (CREATE).

\section{References}

[1] W. Kempton, J. Tomić, J. Power Sources 144 (2005) 268-279.

[2] W. Kempton, S.E. Letendre, Transp. Res. Part D Transp. Environ. 2 (1997) 157175 .

[3] K. Clement-Nyns, E. Haesen, J. Driesen, Electr. Power Syst. Res. 81 (2011) 185192.

[4] J. Tomić, W. Kempton, J. Power Sources 168 (2007) 459-468.

[5] C. Binding, D. Gantenbein, B. Jansen, O. Sundstrom, P.B. Andersen, F. Marra, B. Poulsen, C. Træholt, in: IEEE Power and Energy Society General Meeting, 2010.

[6] A.N. Brooks, Vehicle-to-Grid Demonstration Project: Grid Regulation Ancillary Service with a Battery Electric Vehicle, California Environmental Protection Agency, Air Resources Board, Research Division, 2002.

[7] S. Han, S. Han, Energies 6 (2013) 748-765.

[8] S.B. Peterson, J. Whitacre, J. Apt, J. Power Sources 195 (2010) 2377-2384.

[9] D. Ciechanowicz, M. Leucker, M. Sachenbacher, in: Ökonomische Bewertung von Vehicle-to-Grid in Deutschland, Multikonferenz Wirtschaftsinformatik (MKWI), Braunschweig, 2012.

[10] N. Hartmann, E. Özdemir, J. Power Sources 196 (2011) 2311-2318.

[11] D. Dallinger, D. Krampe, M. Wietschel, IEEE Trans. Smart Grid 2 (2011) $302-$ 313.

[12] S.-L. Andersson, A. Elofsson, M. Galus, L. Göransson, S. Karlsson, F. Johnsson, G. Andersson, Energy Policy 38 (2010) 2751-2762.

[13] B. Jansen, C. Binding, O. Sundstrom, D. Gantenbein, in: First IEEE International Conference on Smart Grid Communications (SmartGridComm), 2010.

[14] Energy Market Authority (EMA), Introduction to the National Electricity Market of Singapore, 2009.

[15] Energy Market Authority (EMA), Singapore Energy Statistics, 2012.

[16] Energy Market Company (EMC), Glossary, 2013. Available from: https://www. emcsg.com/glossary.

[17] Energy Market Company (EMC), Market Data, 2013. Available from: https:// www.emcsg.com/marketdata/priceinformation.

[18] J. Wang, P. Liu, J. Hicks-Garner, E. Sherman, S. Soukiazian, M. Verbrugge, H. Tataria, J. Musser, P. Finamore, J. Power Sources 196 (2011) 3942-3948.

[19] S.B. Peterson, J. Apt, J. Whitacre, J. Power Sources 195 (2010) 2385-2392.

[20] R. Hensley, J. Newman, M. Rogers, Battery Technology Charges Ahead, 2012.

[21] J. Gartner, C. Wheelock, Electric Vehicles: 10 Predictions for 2010, 2009.

[22] M. Huber, A. Trippe, P. Kuhn, T. Hamacher, in: Proceedings of 2012 3rd IEEE PES Innovative Smart Grid Technologies Europe (ISGT Europe), 2012.

[23] Y. Xu, H. Aydt, M. Lees, in: Proceedings of the 2012 ACM/IEEE/SCS 26th Workshop on Principles of Advanced and Distributed Simulation, 2012.

[24] D. Ciechanowicz, H. Aydt, A. Knoll, in: The IASTED International Symposium on Power and Energy, Marina del Rey, USA, 2013. 